\title{
Aufrecht sterben
}

\section{Christina Aus der Au}

Prof. Dr. theol., Mitglied der Redaktion Ethik

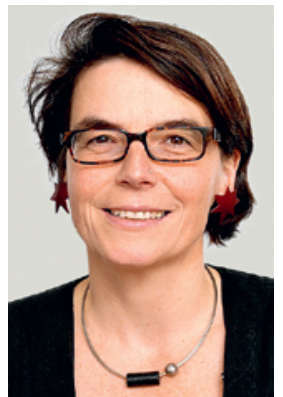

«Let me die in my footsteps», singt Bob Dylan, «before I go down under the ground.» Und er erzählt in seiner lakonisch-poetischen Weise, die ihm 2016 den Literaturnobelpreis eingebracht hat, wie die Menschen sich so sehr ängstigen lassen von Gerüchten und Verschwörungstheorien, dass sie verlernen zu leben. "'Stead of learnin' to live they are learnin' to die», statt dass sie zu leben lernen, lernen sie zu sterben. Er aber will im Lauf sterben, aufrecht, mitten aus dem prallen Leben heraus, und nicht das Leben schon aufgeben, bevor man tatsächlich tot ist.

1962 hat Dylan diesen Song geschrieben, mitten im Kalten Krieg, als er zuschaute, wie Atomschutzbunker gebaut wurden. Und so schrieb er angesichts dieser Bedrohung, kurz vor der Kubakrise, sein Plädoyer, das Leben auszukosten, Bergwasser zu trinken, den Duft wilder Blumen durch die Adern rinnen zu lassen, in den Wiesen zu schlafen und in Frieden mit dem Bruder zusammen die Strasse entlangzugehen. Und dann aufrecht sterben, bevor man unter die Erde in den Bunker geht.

Aufrecht sterben will auch Daniel, der Hausarzt mit dem Krebs im Endstadium. Der Autor Ueli Greminger, bis im letzten Jahr Pfarrer am St.Peter in Zürich, lässt ihn in seinem Buch Der letzte Zug als kritischen, nüchternen und agnostischen Gegenspieler von Peter auftreten, dem selbstkritischen, mit seiner Kirche ringenden Pfarrer [1]. Die beiden werden Freunde, führen lange Gespräche über den Niedergang der Kirche, den Sinn des Lebens und das gute Sterben. Und über die Medizin, welche die Menschen heute unter ihrer Fuchtel hat, wie es früher die Kirche hatte, mit medizinischer Überversorgung, lebensverlängernden Massnahmen und Intensivtherapien, welche die Ärzte, so Daniel, für sich selber in der gleichen Situation ablehnen würden.

Let me die in my footsteps ist sein Lieblingslied. Leben und dann aufrecht von der Bühne abtreten. Und Peter soll ihm dabei helfen, soll sein Sterbebegleiter, Suizidbeihelfer unter dem Deckmantel einer Sterbehilfeorganisation sein. Aber hat er ihm den Trank nur gereicht? Oder doch letztlich gegen seinen Willen eingeflösst? Es gibt dafür eine glaubhafte Zeugenaussage der Ehefrau. Und so kommt der Pfarrer vor Gericht, sitzt in Untersuchungshaft und schreibt sich sein Ringen im Rhythmus von Dylan-Songs von der Seele. Was ist Freiheit? Das gelassene Abtreten von der Bühne, wenn man selber die Zeit für gekommen hält? Der Freundschaftsdienst aus Mitleid, der dafür den Bruch mit seinem Amt in Kauf nimmt? Oder ist Peter damit doch zum pawn in their game, zur Spielfigur, geworden? Aber wessen Spiel? Der Medizin, welche die Sterbehilfe in die Grauzonen auslagert? Der Kirche, die mit der Rede vom Willen Gottes das Problem wegzupredigen versucht? Oder gar das Spiel von Daniel, der ihn damit vor die letzte Herausforderung gestellt hat?

Peter verlässt schliesslich sein Pfarramt und findet seine Freiheit und seinen Frieden im Rebberg. Er wird Winzer und sieht the master's hand in every leaf that trembles, in every grain of sand. Daniel begegnet ihm im Epilog noch einmal im Gespräch «von oben». Und hat das letzte Wort: Die Wahrheit liege nicht in der Freiheit selbst, die erreichen wir nie. Sie liege in der Sehnsucht danach.

Grosse Themen, die nicht zuletzt in diesen Zeiten wieder schmerzlich akut sind. Wie können wir frei und prall leben und sterben? Was ist wichtiger, die Selbstbestimmung oder der Dienst am Nächsten? Wo begleitet die Kirche die Menschen in ihre Tiefen und wo ist sie der Felsbrocken, der auf der Religion liegt? Wo ist die Medizin lebensnotwendig, und wo verhindert sie ein aufrechtes Sterben? Und wo verkriechen wir uns aus Angst in den Bunker unter der Erde?

Das Buch gibt keine eindeutigen Antworten. Aber es stellt Fragen - nicht abstrakt, sondern in eine Geschichte eingebettet. Eine, wie sie eher selten das Leben schreibt, wohl aber ein Autor, der ausloten will, was wir eigentlich meinen mit der Freiheit zum aufrechten Sterben. Und der ringt mit vorgegebenen Antworten, denjenigen der Kirche wie denjenigen der Medizin. Der gestandene Pfarrer und der etablierte Hausarzt sind seine pawns in the game, allerdings beides ältere, gutsituierte, weisse Männer, die gerne in musikalischen und literarischen Anspielungen denken und bei denen die Familie eine geringe Rolle spielt. Ihre sinnlichen Erfahrungen beschränken sich auf den Weingenuss, und sie drehen sich vor allem um sich selber. Die Geschichte darf man durchaus kritisch lesen. Und seine eigenen Antworten - und vielleicht auch Fragen - finden. Lesenswert ist sie allemal.

\section{Literatur}

1 Greminger U. Der letzte Zug. Pfarrer Bodmer unter Verdacht. Zürich: TVZ; 2020 